\title{
The Research on the SME's Collateral Credit Rationing under Loan Risk Compensation Mechanism
}

\author{
Changbing Yang ${ }^{1,2,3}$ Mu Zhang $^{3}$ \\ ${ }^{1}$ Guizhou Institute for Urban Economics and Development, Guizhou University of \\ Finance and Economics, Guiyang Guizhou 550025, China \\ ${ }^{2}$ Guizhou Institution for Technology Innovation \& Entrepreneurship Investment, Guizhou \\ University of Finance and Economics, Guiyang Guizhou 550025, China \\ ${ }^{3}$ School of Finance, Guizhou University of Finance and Economics, Guiyang Guizhou \\ 550025, China
}

\begin{abstract}
This paper discusses the function of loan risk compensation in the collateral credit rationing model.According to the derivation of my model, we find when the bank have some requirements on interest and collateral, at the same time, we add the loan risk subsidy variable into the above model, loan risk subsidy can lower the bank's collateral requirements for the enterprise, therefore, we can conclude that loan risk compensation can effectively alleviate the credit rationing faced by enterprises.
\end{abstract}

\section{Keywords}

Loan Risk Compensation ; The Collateral Credit Rationing Model ; SME ; Government

\section{贷款风险补偿机制下科技型中小企业抵 押品型信贷配给模型研究}

\author{
杨昌兵 ${ }^{1,2,3}$ 张目 ${ }^{3}$ \\ 1 贵州财经大学 贵州城镇经济与发展研究院,贵州 贵阳 550025 \\ 2 贵州财经大学 贵州科技创新创业投资研究院,贵州 贵阳 550025 \\ 3 贵州财经大学 金融学院,贵州 贵阳 550025
}

摘要：本文主要讨论了贷款风险补偿变量在抵押品型信贷配给模型中的作用。根据模型推导 发现，当银行在信贷合同中同时对企业利率和抵押品作出要求时，将贷款风险补偿变量这一 外生变量引入中, 贷款风险补偿可以降低银行对企业的抵押品要求, 因此, 我们可以得出结 论，贷款风险补偿可以有效的缓解企业面临的信贷配给。 
关键词：贷款风险补偿；抵押品型信贷配给；科技型中小企业；政府

\section{1. 引言}

本论文讨论的主要内容是, 在模 型中引入贷款风险补偿变量这一外生 变量的前提下，当银行在信贷合同中 同时对企业利率和抵押品作出要求 时，信贷市场中的信贷配给现象是否 会消失或者遭受信贷配给的企业数目 是否会降低以及贷款风险补偿变量这 一外生变量对科技型中小企业在借贷 中有着怎样的影响。在现实生活中银 行向企业贷款时除了可以调节利率这 一因素之外, 还可以在信贷合同中对 企业有其他诸多要求, 例如: 企业的 资产规模、负债率、抵押品等。众所 周知, 抵押贷款在现代信贷市场中非 常普及。而抵押品在银行向企业贷款 过程中, 也确实起到了至关重要的作 用, 一方面当企业违约时, 银行可以 通过变卖出售来自企业的抵押品, 从 而弥补自己的损失; 另一方面，抵押 品可以对企业自身有约束和激励作 用，约束企业不敢轻易违约，因为一 旦违约企业就会丧失抵押品的所有 权，同时还会严重损害企业自身的信 誉，信誉的损害无疑会加大企业的外 源融资成本, 尤其是信贷成本。企业 出于以上两点考虑自然会努力工作, 以期如约完成合约。

由于抵押在实践中被广泛应用， 以期解决信贷市场中借贷双方严重的 信息不对称问题，鉴于以上现实，国 内外诸多学者对该领域有着广泛而深 入的研究, 但是由于模型设计以及前 提假设的不同, 最后所得出的结论也 大相径庭。通过对相关文献的阅读与 思考，笔者发现上述理论思想主要可 以归纳为以下两种观点, 一种是以 Stiglitz 和Weiss 等为代表, 认为即 使将抵押品加入信贷条约中, 均衡信
贷配给依旧会存在; 另外一种是以 Bester 等为代表, 认为如果允许银行 同时在信贷合约中调整利率和抵押品 要求, 则信贷配给就不会存在, 而会 形成分离均衡。下面笔者将详细介绍 这两种观点。

Stiglitz 和 Weiss (1981) ${ }^{[1]}$ 认为 有两方面的原因导致银行即使将抵押 品作为信贷合同的条款, 信贷市场上 均衡信贷配给依旧会存在。对于某些 后来的研究者认为抵押品可以充当区 分借款者风险类别这一说法,

Stiglitz 和 Weiss (1987, 1987, 1992 $)^{[2][3][4]}$ 在后期又陆 续建立了一些理论模型深入研究讨论 了相关问题，他认为借款厂商之间在 多个维度上存在区别，仅仅单靠抵押 品这唯一特征, 难以将不同风险类型 的企业进行有效区分，当且仅当只考 虑借款厂商某一方面的区别, 例如各 借款厂商自有资产，那么才有可能通 过利率和抵押品这一简单合约将不同 风险类别的厂商加以区分。当然，倘 若借款厂商之间只在两个维度存在区 别, 银行仍可能采用一个较复杂的合 约来完全区分这些风险类别不同的借 款者。但是, 核心问题在于, 只要借 款厂商的特征变量维数多余合约变量 空间维数, 银行就难以获得借款厂商 的完备信息。Wette (1983) ${ }^{[5]}$ 在 S-W 模型的基础上，进一步考察了抵押品 在均衡信贷配给中的作用。

对于上述观点, 许多学者给出了 完全不同的见解。他们认为在信息不 对称条件下, 如果贷款者能够变动抵 押要求, S-W 模型中的信贷配给并不必 然发生。Bester $(1985,1987)^{[6][7]}$ 认 为如果在竞争信贷市场状态下，允许 银行同时调整利率和抵押品要求, 那 么均衡状态下就不会产生信贷配给。 
Chan 和 Kanatas（1985） ${ }^{[8]}$ 认为，抵押 可以起到信号发送的作用，即可以间 接的缓解借款者和贷款者之间的信息 不对称问题。Besanko 和 Thakor (1987) ${ }^{[9]}$ 在模型中假定只有逆向选择 存在作用, 道德风险的作用为零, 银 行在信贷合同中会考虑包括利率在内 的多种因素, 主要是抵押品。Riley (1987) ${ }^{[10]}$ 则认为高质量的借款者有 办法发出信号显示他们与低质量借款 者的区别。

Hung-jen wang (2000) ${ }^{[11]}$ 认为担 保与信贷风险正相关。

以上主要是国外一些学者的理论 研究成果, 国内部分学者在信贷配给 领域也做了一些探索性工作。王霄和 张捷（2003） ${ }^{[12]}$ 根据其建立的模型认 为, 在信贷配给中被剔除的主要是资 产规模小于银行所要求的临界抵押品 价值的中小企业和部分高风险企业。

金俐（2004） ${ }^{[13]}$ 在论文中讨论了在只 考虑道德风险的情况下, 抵押品与信 贷配给之间的相互关系, 如果借款企 业不能够提供充足的抵押品, 那么, 即使净现值为正的项目也依旧不会获 得银行的贷款。胡红星和张亚维 （2005） ${ }^{[14]}$ 指出在多样性的信贷合同 组合中, 可以通过贷款利率、抵押品 作为甄别机制从而达到斯宾塞-莫里斯 分离均衡, 并分析了其存在的条件与 范围。李文豪 (2006) ${ }^{[15]}$ 通过研究发 现, 当企业能够提供足够价值的担保 品时, 市场上信贷配给的现象就会减 弱, 反之则不断上升。叶谦 (2006) ${ }^{[16]}$ 从契约设计和激励机制的角度, 分别 分析了了抵押品、贷款利率和贷款规 模等变量如何影响契约设计, 以及对 于借款者风险类型的辨别起到怎样的 作用。刘雪峰（2010） ${ }^{[17]}$ 利用仿真技 术建立人工信贷市场，模拟了不同抵 押品要求条件下银行的利润水平变化 情况、信贷配给程度变化情况以及企 业资产变动情况。
综上所述, 笔者发现国内外学者 对于信贷配给问题的研究主要集中于 对借贷双方进行讨论, 而没有考虑政 府介入的情形。本文与前面文献作者 最大的区别就是在考虑借贷双方的情 况下，同时引入第三方政府贷款风险 补偿因素, 考察了贷款风险补偿因素 对企业信贷配给的影响。

\section{2. 模型假设}

（1）每个企业自有资产为 $A$ ，且 $A$ 在 $[0, \bar{A}]$ 之间均匀分布。

（2）根据企业自有资产的多少将 企业分为规模不同的两类企业，第一 类 $j$ 企业拥有的自有资产为 $A_{j}^{l}$, 第二 类的 $k$ 企业拥有的自有资为 $A_{k}^{s}$, 其中 $A_{i}^{j}>A_{k}^{s}$, 即第一类企业的规模大于第 二类企的规模。

（3）信贷市场是竞争市场，即在 均衡状态下银行的利润为零。

（4）银行和借款企业均为风险中 性。

（5）企业自身没有任何流动资 产，企业只有向银行贷款才能对技术 开发项目进行投资且每个项目投入的 资金固定，投入的固定资金表示为 $B$ 。

（6）当企业违约时, 银行处理企 业所抵押的资产时一定会承担相应的 清算处理费用, 为了便于后面模型推 导假设清算费用为抵押品价值的一个 固定比例 $h, h C$ 即表示清算费用, $0 \leq h \leq 1, C$ 表示抵押品价值且 $C>0$, 因此, 银行清算抵押品之后能够获得 的价值补偿为 $(1-h) C$, 令 $t=1-h$, 所以 银行清算抵押品之后能够获得的价值 补偿为 $t C, 0 \leq t \leq 1$ 。

（7） $E$ 表示企业经营者处于努力 状态比经营者处于懒惰状态多付出的 成本; $p_{h}$ 表示企业经营者处于努力状 
态下，技术开发项目成功的概率; $p_{l}$ 表示企业经营者处于懒惰状态下技术 开发项目成功的概率, 其中 $p_{h}>p_{l}$, $\Delta p=p_{h}-p_{l}$; 当技术开发项目成功时企 业获得收益 $R$, 失败时则收益为零, 技术开发项目只有成功与失败两种可 能; 若企业投资技术开发项目，同时 管理者努力经营则如下不等式关系成 立: $p_{h} R-E>B>p_{l} R$ 。

（8）银行获得单位可贷资金的成 本为 $b$, 即储户在银行存款利率为 $b$; 银行每单位贷款获得的收益为 $r$, 即银 行的贷款利率为 $r$; 为了便于后面的模 型推导设 $H=B(1+r), \quad M=B(1+r), \quad H$ 表示借款企业不违约的情况下归还银 行的本息和, $M$ 表示银行为了获得该 笔可贷资金支付给储户的本息和。

（9）银行给每个贷款申请者发放 贷款的概率相等。由于企业是否努力 经营是私人信息, 为避免道德风险, 银行需要提供一个激励相容信贷合 同, 鉴于本文分析的重点在抵押上, 因此, 文章当中不会考虑企业努力经 营能够获得足够高的回报, 从而在贷 款过程中不需要抵押这种极端情况。

\section{3. 信贷配给模型建立与分析}

设银行提供贷款合同 $\left\{r_{i}, C_{i}\right\}$ 给企 业, $\left\{r_{i}, C_{i}\right\}$ 表示借款企业 $i$ 所面临的贷 款利率 $r$ 和抵押品要求 $C$ 的组合。对于 企业而言，贷款合同必须满足激励相 容约束条件和参与约束条件; 对于银 行而言, 贷款合同必须使得银行的利 润为非负, 因此, 一个可行的抵押信 贷约束条件可以用如下公式表述:

对企业而言:

企业激励相容约束条件:

$p_{h}(A+R-H)+\left(1-p_{h}\right)(A-C)-E \geq p_{l}(A+R-H)+\left(1-p_{l}\right)(A-C)$
从上述不等式可以推导出如下关 系式:

$$
H \leq R-E / \Delta p+C
$$

当等号成立时可以获得企业激励相容 条件下企业愿意接受的最高贷款利 率。

企业的参与约束条件:

$$
p_{h}(A+R-H)+\left(1-p_{h}\right)(A-C)-E \geq A
$$

根据上式可以推导出如下关系式:

$$
p_{h}(R-H)-\left(1-p_{h}\right) C-E \geq 0
$$

对银行而言, 银行只存在参与的 约束条件而不存在激励相容约束条 件, 即银行约束条件关系式如下:

$$
p_{h} H+(t C+\lambda \theta B)\left(1-p_{h}\right)-M \geq 0
$$

其中 $\theta$ 表示贷款损失准备率（常数）, $\lambda$ 表示政府对银行贷款风险补偿率, $\lambda \in[0,1]$ 。

抵押贷款可行的约束条件, 即借 款企业若想从银行获得贷款, 其自有 资产必须满足的最低标准:

$$
A \geq C
$$

令 3.2 式的等式成立, 同时将成立之 后的表达式带入 3.5 式，同时令 3.5 式的等式也成立, 于是我们可以得到 如下关系式:

$$
p_{h}\left[R-E / \Delta p+C_{0}\right]+\left(t C_{0}+\lambda \theta B\right)\left(1-p_{h}\right)-M=0
$$

其中 $C_{0}$ 表示银行期望利润为零时 的抵押品价值, 根据 3.7 式我们可以 得到如下关系式:

$$
C_{0}=\frac{M-p_{h}(R-E / \Delta p)-\left(1-p_{h}\right) \lambda \theta B}{p_{h}+\left(1-p_{h}\right) t}
$$

因为前面假定 $C>0$, 所以知 $M-p_{h}(R-E / \Delta p)-\left(1-p_{h}\right) \lambda \theta B>0 。$

根据 3.8 式, 我们可以推导出如下两 个关系式:

$$
\frac{d C_{0}}{d t}=-\frac{M-p_{h} R+p_{h} E / \Delta p-\left(1-p_{h}\right) \lambda \theta B}{\left[p_{h}+\left(1-p_{h}\right) t\right]^{2}}\left(1-p_{h}\right)<0
$$




$$
\frac{d C_{0}}{d \lambda}=-\frac{\left(1-p_{h}\right) \theta B}{p_{h}+\left(1-p_{h}\right) t}<0
$$

根据 3.8 式我们知道 3.8 式的分 子为正, 因此 3.9 式整体小于零; 3.10 式显然小于零。

将 3.8 式带入 3.2 式, 可以得到 银行能够获得的最优偿还值:

$$
H_{0}=R-\frac{E}{\Delta p}+\frac{M-p_{h}(R-E / \Delta p)-\left(1-p_{h}\right) \theta B}{p_{h}+\left(1-p_{h}\right) t}
$$

\section{4. 结论与对策}

通过对上述模型分析, 我们可以 得出如下一些结论：如果按照资产规 模给企业进行分类, 银行只知道各企 业资产的规模是均匀分布，但是并不 了解各企业具体的分类情况, 那么当 $C_{0}>A_{j}^{i}$, 所有企业都将被配给, 即没 有任何企业可以从银行获得贷款; 当 $C_{0}$ 处于 $A_{j}^{i}$ 之间, 将有部分第一类企业 遭受配给, 另外一部分企业能够获得 银行贷款，第二类企业将会全部遭受 配给; 当 $C_{0}$ 处于 $A_{k}^{s}$ 之间时, 则部分第 二类企业将遭受配给, 另外一部分企 业能够获得银行贷款，所有一类企业 都能够获得贷款; 当 $A_{k}^{s}>C_{0}$ 时, 那么 所有一类和二类企业都将会获得银行 贷款，没有任何企业会遭受信贷配 给。如果银行知道每个企业具体分类 情况, 那么银行提供分类贷款合同能 够达到利润最大化。除此之外, 我们 还知道银行清算企业抵押品的成本越 高, 银行对企业要求的抵押品价值越 高; 贷款风险补偿变量的引入能够有 效缓解科技型中小企遭受信贷配给。

\section{参考文献}

[1] Stiglitz J, Weiss A. Credit Rationing in Markets with Imperfect Information[J]. American Economic Review,1981,71(3):393-410.

[2] Stiglitz J, Weiss A. Credit Rationing: Reply[J]. The American Economic Review,1987,77(1):228-231.

[3] Stiglitz J, Weiss A. Macroeconomic Equilibrium and Credit Rationing[R]. NBER Working Paper, 1987, N0. 2164

[4] Stiglitz J, Weiss A. Asymmetric Information in Credit Markets and Its Implications for Macroeconomics[J]. Oxford Economic Papers, 1992, 44(2):694724.

[5] Wette H. Collateral and credit rationing in markets with imperfect information: Note[J]. American Economic Review, 1983,73(3):442445.

[6] Bester H. Screening vs. rationing in credit markets with imperfect information[J]. American Economic Review, 1985,75 (4):850-855.

[7] Bester H.The Role of Collateral in Credit Market with Imperfect Information[J].European Economic Review, 1987,31(2):887-899.

[8] Chan Y, Kanatas G. Asymmetric Valuations and the Role of Collateral in Loan Agreements[J]. Journal of Money Credit and Banking, 1985,17(1):84-95.

[9] Besanko D, Thakor A V. Collateral and rationing: sorting equilibrium in monopolistic and competitive credit markets[J]. International Economic Review, 1987,28(3):671-689.

[10] Riley J.G. Credit Rationing :A Further Remark[J].The American Economic Review, 1987, 77(1):224227.

[11] Huang-Jen Wang. Symmetric Information and Credit Rationing: 
Graphical Demonstration[J]. Financial Analysts Journal,56(2):8595.

[12] 王宵,张捷.银行信贷配给与中小企 业贷款一一一个内生化抵押品和 企业规模的理论模型 $[\mathrm{J}]$. 经济研 究,2003,8(7):68-75.

[13] 金俐.信贷配给：微观基础与货币 政策含义研究 [D]. 上海: 复旦大 学, 2004 .

[14] 胡红星,张亚维.中小企业信贷配给 的综合模型 $[\mathrm{J}]$. 数量经济技术经济 研究,2005,6(7):23-32.

[15] 李文豪.我国银行信贷配给程度及 其对货币政策效果的影响[D].杭州: 浙江大学, 2006 .

[16] 叶谦.信贷配给的机制影响与制衡 研究[D].武汉:华中科技大学,2006.

[17] 刘雪峰.中小企业信贷配给问题及 人工信贷市场仿真研究 [D]. 天津: 天津大学, 2010 . 